\title{
A dentigerous cyst in a patient treated for an odontogenic myxoma of the maxilla: A case report
}

\section{Torbiel zawiązkowa zęba u pacjenta leczonego \\ z powodu śluzaka zębopochodnego szczęki - opis przypadku}

\author{
Patrycja Proc ${ }^{1, A-D}$, Małgorzata Zubowska ${ }^{2, A-D}$, Anna Janas-Naze ${ }^{3, B, E}$ \\ ${ }^{1}$ Department of Pediatric Dentistry, Medical University of Łodź, Łodź, Poland \\ ${ }^{2}$ Department of Pediatrics, Oncology, Hematology and Diabetology, Medical University of Łódź, Łodź, Poland \\ ${ }^{3}$ Department and Clinic of Oral Surgery, Medical University of Łodź, Łodź, Poland \\ A - research concept and design; $\mathrm{B}$ - collection and/or assembly of data; $\mathrm{C}$ - data analysis and interpretation; \\ $D$ - writing the article; $E$ - critical revision of the article; $F$ - final approval of article
}

Address for correspondence

Patrycja Proc

E-mail: patrycja.proc@umed.lodz.pl

Funding sources

none declared

Conflict of interest

none declared

Received on September 11, 2016

Revised on September 22,2016

Accepted on September 30, 2016

\begin{abstract}
Tumors of the oral cavity are of various origins and can be signs of non-invasive cysts or malignant neoplasms.

The paper describes the case of a 9-year-old boy with a tumor in the right side of the maxilla. Having been treated for an odontogenic myxoma at the age of 3 , the patient was included in a national program assessing the health of children who had undergone anticancer treatment. The boy remained under oncological supervision, and the tumor was found again in the same region a few years later. It was diagnosed as a dentigerous cyst and surgically excised. In addition, when the patient was 9 several changes in dentition were found that were typical following anticancer therapy: no tooth germs were observed for teeth 13, 35 and 45, and microdontic teeth 25 and 47 were noted. These changes could be attributed to the chemotherapy performed in early childhood. Tumors appearing in the oral cavity al ways require an in-depth assessment of their nature and origin. Chemotherapy elicits late complications in tooth development in children.
\end{abstract}

Key words: child, myxoma, dentigerous cyst

Słowa kluczowe: dziecko, śluzak zębopochodny, torbiel zawiązkowa

D0I

$10.17219 / \mathrm{dmp} / 65514$

Copyright

○ 2017 by Wroclaw Medical University

and Polish Dental Society

This is an article distributed under the terms of the

Creative Commons Attribution Non-Commercial License

(http://creativecommons.org/licenses/by-nc-nd/4.0/) 
A cyst is defined as a pathological space within soft tissues or bones that contains a liquid and is lined with an epithelial lining. The most common odontogenic cysts are radicular cysts $(62 \%)$, dentigerous cysts (31\%) and primordial cysts $(3 \%)$. They are more common in the mandible ( $52 \%$ of cases) than in the maxilla ( $46 \%$ of cases), with the remaining cases $(2 \%)$ found in both jaws. ${ }^{1}$ In an analysis of the incidence of cysts among patients treated between 1996 and 1999 in the Department of Dental Surgery in Warszawa, Kozarzewska et al. found 340 such cases, 174 (51.2\%) in women and $166(48.8 \%)$ in men, with developmental cysts in $9.5 \%$ of them. ${ }^{2}$

Kramer and Pindborg propose that dentigerous cysts are epithelial odontogenic cysts that arose from the dental lamina following disturbances in the process of odontogenesis. ${ }^{3}$ They are accompanied by impacted, embedded or otherwise unerupted teeth. ${ }^{4,5}$ The cysts may have an inflammatory origin from a source such as periapical inflammation from non-vital teeth. ${ }^{6}$ They also appear during the course of some genetic disorders, such as Gorlin syndrome or cleidocranial dysplasia., ${ }^{5,7}$

The clinical symptoms of dentigerous cysts include expansion of dento-alveolar bone, facial asymmetry, divergence of adjacent tooth roots, dislocation of teeth, disturbances in teething, malocclusion or local inflammation. ${ }^{2,5,9}$ The cysts are typically found accidentally during routine radiographic examinations as well-defined unilocular or multilocular radiolucent lesions. ${ }^{8}$

The treatment of cysts is surgical. According to traditional terminology, Partch I refers to total excision of the cyst with its follicle and the tooth germ inside, while Partch II refers to a 2-step method of marsupialization or cystotomy. ${ }^{8}$ In cases of larger lesions, several modifications can be used, mostly based on decompression by fenestration of the tumor, leading to a gradual reduction of the cyst before its final excision. ${ }^{4}$

While the prognosis for surgical treatment is good, a cyst can recur if many epithelial cells remain. During surgery, the tooth germ is also removed from inside the cyst. A lack of treatment can lead to bone perforation or metaplasia of the cyst to the neoplasm. ${ }^{9-12}$

\section{Case report}

In January 2015, a 9-year-old boy (F.T.) was admitted to the Clinic of Pediatrics, Oncology, Hematology and Diabetology at the Medical University of Łodź (Poland). He had been under regular supervision since 2009 as part of a national program supported by the National Health Ministry assessing the health of children following anticancer treatment. In 2009, at the age of 3, the boy was treated for a tumor of the right maxillary sinus. The tumor was totally excised in July 2009; the initial histopathological diagnosis of rhabdomyosarcoma led to a recommendation of chemotherapy according to the
CWS protocol. By the time the diagnosis was verified, 3 full cycles of chemotherapy had been completed. After gaining a final histopathological diagnosis from the international Sarcoma Coordinator for Cancer Treatment, the diagnosis was changed from sarcoma to myxoma, and the invasive treatment was suspended. The boy remained under observation by the Clinic of Oncology with regular magnetic resonance imaging (MRI) examinations; no sign of relapse was found in the right maxillary sinus.

A few days before the January 2015 visit, the patient, now aged 9, had reported a change in the shape of the alveolar process of the upper right side of the maxilla. An MRI was performed in the Clinic of Oncology using T1/T2-weighted imaging with a Fast Spin Echo (FSE) sequence, a T1-weighted FLAIR sequence with fat suppressed (FS) and a T1-weighted FS sequence following intravenous infusion of the contrast medium. The MRI revealed no relapse of myxoma, and showed that the paranasal sinuses were also free from changes. However, in the region of tooth 12 , a $11 \times 6 \mathrm{~mm}$ tumor was noticed with no inflammatory changes in the surrounding bone (Fig. 1). Digital palpation indicated that the submandibular and cervical lymph nodes were not enlarged, and that a small polyp of mucous membrane, about $7 \mathrm{~mm}$ in diameter, with no neoplastic traits, was present in the apex of the left maxillary sinus. The polyp had been visible during earlier MR imaging.

An initial diagnosis of odontogenic cyst was made, and the patient was directed to the Department of Pediatric Dentistry of the Medical University of Łódź for further diagnosis and treatment.

The patient was admitted to the Department of Pediatric Dentistry for an urgent procedure in February 2015. A clinical investigation revealed the presence of a non-painful

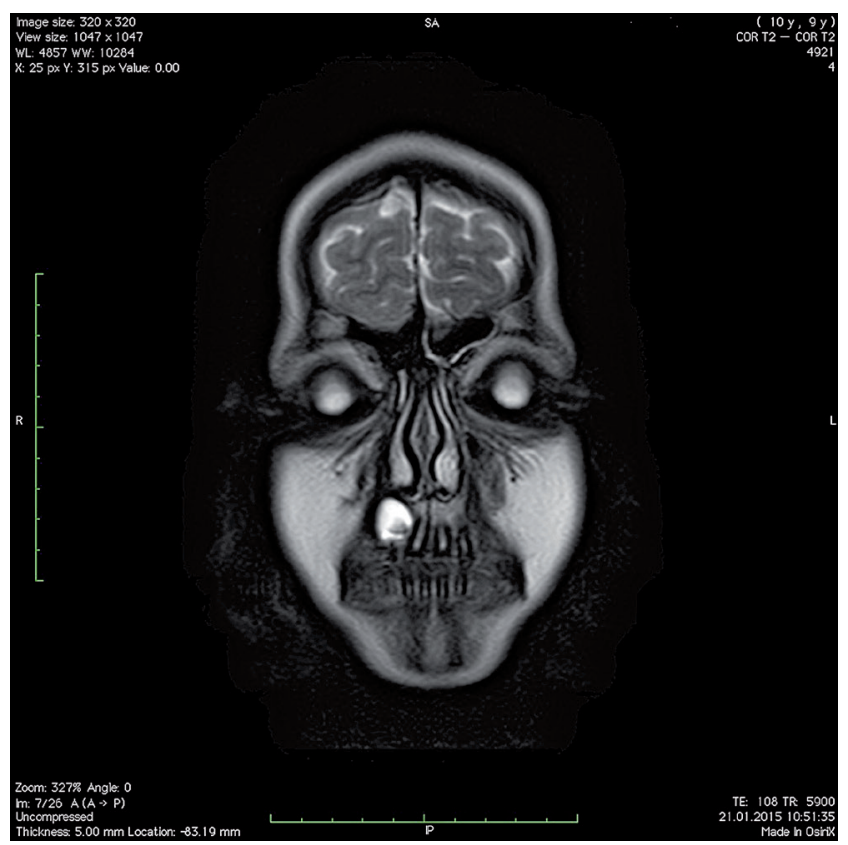

Fig. 1. CT of the head of the 9-year-old boy 


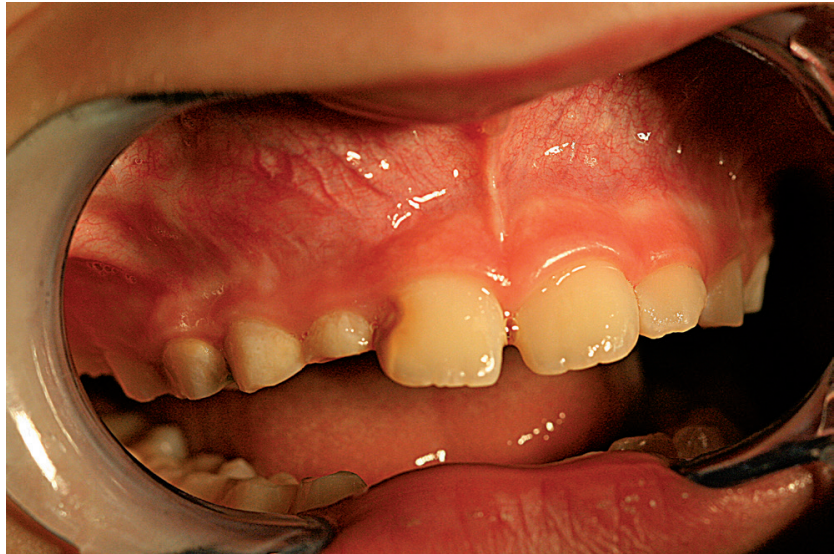

Fig. 2. Intraoral view of the tumor in the nine-year-old boy

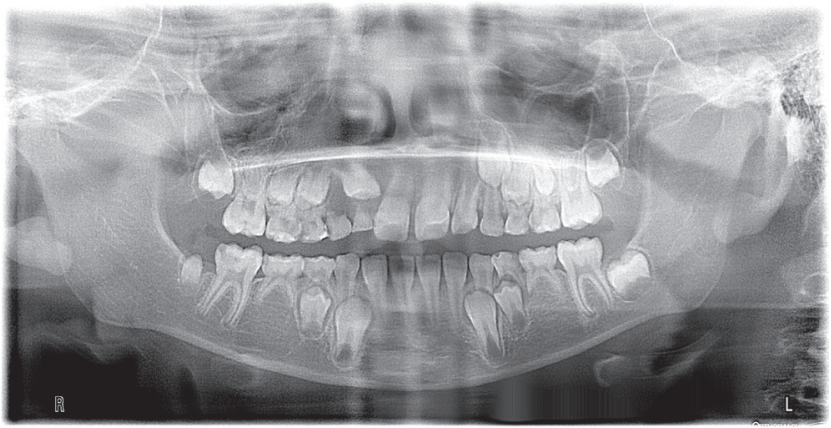

Fig. 3. Panoramic radiograph taken before treatment of the nine-year-old boy: cyst with the crown of tooth 12 on the right side

tumor with unchanged mucous membrane in the region of teeth 52, 53 and 54 (Fig. 2). The teeth were not tender to percussion, and the reaction of their pulp was correct. In addition, a retained tooth 52 was noticed, while permanent tooth 22 had already fully erupted on the opposite side of the arch. A panoramic radiograph was performed, and an impacted tooth 12 was observed inside the tumor (Fig. 3); the root of tooth 11 was displaced. On the basis of the radiograph, a dentigerous cyst was diagnosed (cystis follicularis). The patient was directed to the Department of Oral Surgery of the Medical University of Łódź, where the cyst was excised. During the procedure, teeth 52, 53, 54 and 12 were removed under general anesthesia (Figs. 4 and 5). The histopathological results confirmed the clinical diagnosis.

The radiograph also revealed several dental anomalies. The dentition lacked germs for teeth 13, 35 and 45, and microdontic teeth 25 and 47 were found.

\section{Discussion}

The occurrence of a dentigerous cyst in the same region as a neoplasm may suggest that the presence of the neoplasm is related to the inception of the cyst following

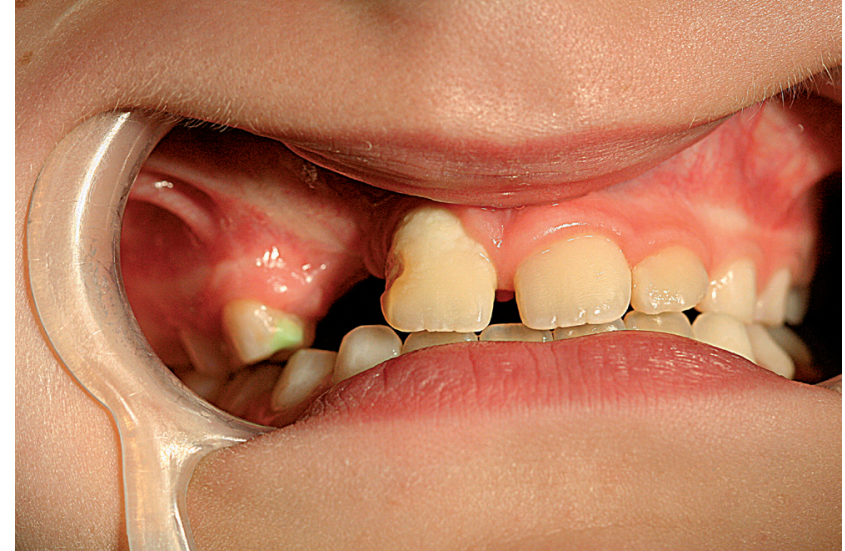

Fig. 4. Intraoral view of the nine-year-old boy's dentition two months after surgery

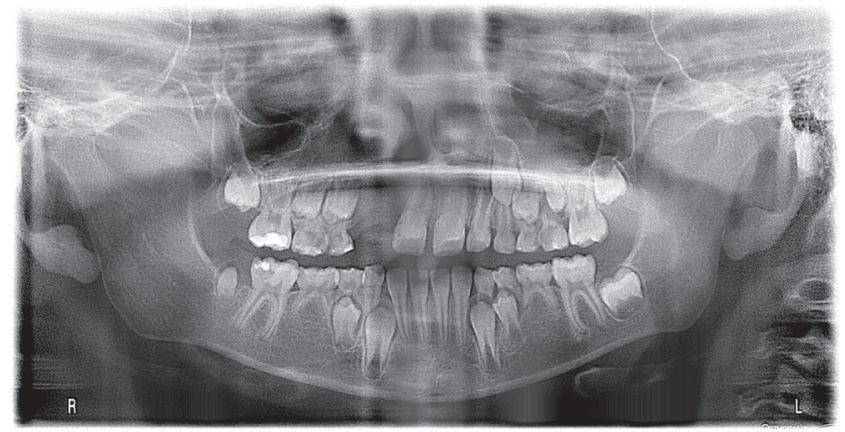

Fig. 5. Panoramic radiograph taken two months after treatment of the nine-year-old boy; the absence of tooth germs for teeth 13, 35 and 45 and microdontic teeth 25 and 47 can be noted

cancer treatment. The inflammatory condition caused by the tumor, or mechanical damage to the dentigerous lamina connected with surgery, may have initiated the cyst.

On the other hand, several studies have reported a connection between the occurrence of odontogenic cysts and neoplasms, and various authors have noted that lesions which appear as dentigerous cysts may have a component of ameloblastic changes in their lining., ${ }^{9,13,14}$ Mucussecreting cells or even a mucoepidermoid carcinoma may arise in the wall of a cyst. ${ }^{8}$ It has also been documented that a dentigerous cyst may transform, or be a predictor of odontogenic keratocysts in later years. ${ }^{8,15}$ These observations might indicate that a connection exists between various pathological processes which share similar origins in the same part of the bone.

In the present case, the decision to perform total enucleation of the dentigerous cyst followed a heated discussion in which the authors compared the use of total incision with a 2-stage treatment. The 2-stage treatment seemed to be more favorable, as many studies stress the advantages of more conservative treatment, preserving the tooth inside the cyst, especially in patients of developmental age. ${ }^{1,4}$ In addition, the patient already lacked a few teeth, including an adjacent upper canine. However, in the light 
of the aforementioned link between different pathological processes and the fact that the boy had already suffered from cancer, it was decided to remove all the cells of the cyst by more invasive treatment. It should be noted that the diagnosis was not certain until the histopathological verification.

The odontogenic myxoma (OM) found in the patient at the age of 3 is a benign neoplasm that represents around $3-6 \%$ of all odontogenic tumors. It can be locally invasive and can be found in both jaws with similar incidence. ${ }^{10,12,16}$ It originates from odontogenic ectomesenchyme or undifferentiated mesenchymal cells in the periodontal ligament. ${ }^{8}$ In a Polish population, Stypulkowska found myxoma to be present more commonly in the mandible than the maxilla, and more frequently in males than females $(1: 0.7) .{ }^{17}$ The majority of cases are found in the second or third decades of life, but are also occasionally found in those below the age of 10 (5-7\% of cases). ${ }^{8,18}$ While the initial recognition of the tumor is mostly based on radiographs, this is followed by computer tomography (CT) or MRI. The final diagnosis is based on histological results. McDonald-Jankowski et al. reported that the likelihood of perforation and the pattern of the septa in the myxoma are better displayed by $\mathrm{CT}$, while the tooth displacement and root resorption are more reliably observed on conventional radiographs. ${ }^{19}$

In the present case, both tumors were initially diagnosed by MRI. In the case of the cyst, a relapse of myxoma was excluded during MR imaging. However, the dentigerous cyst with a tooth inside was visible only in a conventional radiograph. It is difficult to distinguish odontogenic myxomas from similar tumors, and a number of diagnostic errors have been described. ${ }^{20}$ Myxomas might be mistaken for dentigerous inflammation or a malignant neoplasm; for example, Basile and Lin described a case of odontogenic myxoma mimicking a fibro-osseous process. ${ }^{21}$ On the other hand, Kali et al. reported a gnathic desmoplastic fibroma mimicking a dentigerous cyst. ${ }^{22}$

The patient described in the present study had received 3 rounds of chemotherapy before the final, more favorable diagnosis of the tumor was made, and several dental anomalies were found in the panoramic radiograph taken a few years after anticancer treatment. The missing upper right canine (tooth 13) was probably a complication of myxoma excision from the upper right sinus. However, the lack of premolars 35 and 45 and the microdontia of teeth 25 and 47 , not directly connected with the site of the tumor, might have been a complication of chemotherapy. In an examination of the impact of chemotherapy on the incidence of dental anomalies like hypodontia, microdontia or short roots, Proc et al. noted a significantly higher incidence of missing teeth in patients who had undergone chemotherapy in early childhood than in the controls ( $31.14 \%$ vs $9.21 \%)$, as well as a greater incidence of microdontic teeth (36.06\% vs $2.87 \%){ }^{23}$

Although hypodontia is most often attributed to genetics, in the present case an interview with the immediate family members excluded this possibility. The etiology of microdontic teeth is not well evidenced; however, microdontia is believed to be mostly caused by harmful factors disturbing odontogenesis. ${ }^{23}$ The patient in the present study had received anticancer treatment at the age of 3 , which is known to be a critical age for the development of premolar and second molar teeth. While microdontic premolars are most often found in patients treated within the age range of 19-24 months, the 31-42 month period is also known to be one of increased risk for premolars. ${ }^{23}$ Microdontic second molars are most often found in patients treated in the 31-36 month age range, which includes the age at which the patient in this study underwent chemotherapy.

\section{Conclusions}

Tumors appearing in the oral cavity always require an in-depth assessment of their nature and origin.

Chemotherapy elicits late complications in tooth development in children.

\section{References}

1. Pawlak W, Kubasiewicz-Ross P, Pałka $Ł$, Zarzycki R. Cystic lesions of the jaws treated surgically in the Department of Maxillofacial Surgery Wroclaw Medical University in the years 2004-2007. Dent Med Probl. 2009;46:49-53 [in Polish].

2. Kozarzewska M, Popowski W, Wojtowicz A. Epidemiological analysis of dentigerous cysts in material of Oral Surgery Department Medical University of Warsaw by years 1996-1999. Nowa Stomatol. 2001;6:2, 15-18 [in Polish].

3. Kramer IRH, Pindborg JJ, Shear M. The WHO histological typing of odontogenic tumorous. A commentary on the second edition. Cancer 1992;70:2988-2994.

4. Sobczak-Zagalska H, Emerich K. Dentigerous cyst - case reports and proposed treatment. Magazyn Stomatol. 2015;25:1, 31-37 [in Polish].

5. Puacz P, Koczorowski M, Kaczmarek I, Osmola K. Dentigerous cyst associated with maxillary canine as a reason of occlusion defect. Dev Period Med. 2013;1:72-76 [in Polish].

6. Benn A, Altini M. Dentigerous cysts of inflammatory origin. A clinicopathologic study. Oral Surg Oral Med Oral Pathol Oral Radiol Endod. 1996;81:203-209.

7. Błochowiak K, Pluskota J, Grajewski S, Sokalski J. Rare case of a huge odontogenic cyst of the mandible. Dent Forum 2013;41:144-49 [in Polish].

8. Mc Donald RE. Tumors of the oral soft tissues and cysts and tumors of the bone. [In:] Dentistry for the Child and Adolescent. Eds.: Dean JA, Avery DR, Mc Donald RE. Mosby, Elsevier, 2011, 135-141.

9. Ratajczyk M, Sowa W, Walter A. Molecular basis for formation of the odontogenic inflammatory cysts - review of literature. Dent Med Probl. 2010;47:496-501 [in Polish].

10. Aquillino RN, Tuji FM, Eid LM, Molina OF, Joo HY, Net FH. Odontogenic myxoma in the maxilla: A case report and characteristic on CT and MR. Oral Oncol. 2006;42:133-136.

11. Borgiel-Marek $H$, Jędrusik-Pawłowska $M$, Drugacz J, Malara $P$, Wodołażski A, Mazur M. Myxoma of the maxilla and mandible - a report of two cases and literature review. Czas Stomatol. 2005;56:667-672 [in Polish].

12. Tkaczuk AT, Bhatti M, Caccamese JF, Ord RA, Pereira KD. Cystic lesion of the jaw in children. JAMA Otolaryngol Head Neck Surg. 2015;141:834-839.

13. Cankurtaran C, Branstetter BF, Chiosea SI, Barnes EL Jr: Ameloblastoma and dentigerous cyst associated with impacted mandibular third molar tooth. Radio Graphics 2010;30:1415-1420. 
14. Mc Millan MD, Smillie AC. Ameloblastomas associated with dentigerous cysts. Oral Surg. 1981;51:489-496.

15. Tsukamoto G, Sasaki A, Akiyama T, Ishikawa T, Kishimoto K, Nishiyama A, Matsumura T. A radiologic analysis of dentigerous cysts and odontogenic keratocysts associated with a mandibular third molar. Oral Surg Oral Med Oral Pathol Oral Radiol Endod. 2001;91:743-747.

16. Singaraju S, Wanjari SP, Parwani RN. Odontogenic myxoma of the maxilla: A report of a rare case and review of the literature. $J$ Oral Maxillofac Pathol. 2010;14:19-23.

17. Stypulkowska J. Odontogenic tumors and neoplastic-like changes of the jaw bone: Clinical study and evaluation of treatment results. Folia Medica Cracov. 1998;39:135-141 [in Polish]

18. Noffke CE, Raubenheimer EJ, Chabikuli NJ, Bouckaert MM. Odontogenic myxoma: Review of the literature and report of 30 cases from South Africa. Oral Surg Oral Med Oral Pathol Oral Radiol Endod. 2007;104:101-109.
19. MacDonald-Jankowski DS, Yeung RW, Li T, Lee KM. Computed tomography of odontogenic myxoma. Clin Radiol. 2004;59:281-287.

20. Gupta P, Jawanda K, Narula R, Singh J. Inflammatory dentigerous cyst mimicking a periapical cyst. J Int Clinic Dent Res Org. 2016;8: 63-66.

21. Basile JR, Lin YLA. Case of odontogenic myxoma with unusual histological features mimicking a fibro-osseous process. Head Neck Pathol. 2010;4:253-256.

22. Kalia V, Kaur S, Vashisht D. Gnathic desmoplastic fibroma mimicking a dentigerous cyst: A case report J Maxillofac Oral Surg. 2015;14 (Suppl 1):150-153.

23. Proc P, Szczepańska J, Skiba A, Zubowska M, Fendler W, Młynarski $W$. Dental anomalies as late adverse effect among young children treated from cancer. Cancer Res Treat. 2016;48: 658-667. 